FROM PLACE TO PLACE IN THE SOUND AND THE FURY: THE SYNTAX OF INTERROGATION

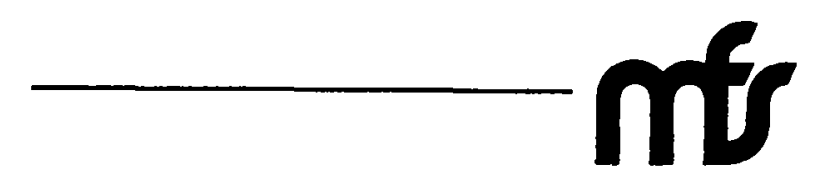

\title{
Cheryl Lester
}

Because the individual sections of The Sound and the Fury are not intelligible in themselves, readings of this novel depend on the complex interplay between the sections. For this reason, the analytical approach generally brought to bear on this novel can analyze, in its most successful application, only the critical or fictional synthesis into which its individual sections have been read. Yet studies of The Sound and the Fury that proceed from section to section, like those of Olga Vickery or Wolfgang Iser, or that concentrate on one section alone, like that of George Stewart and Joseph Backus, give the mistaken impression that the significance of the novel is the sum of four independently meaningful parts, individually calculated and added up.

Analyses of The Sound and the Fury generally refer to the relationship among the sections only in order to characterize the development of the novel as a whole. The novel is most often said to shift, particularly with the fourth section, from obscurity to clarity, from privacy to universality, or from subjectivity to objectivity. Describing this development, André

Modern Fiction Studies, Volume 34, Number 2, Summer 1988, Copyright (C) by Purdue Research Foundation. All rights to reproduction in any form reserved. 
Bleikasten writes, "No longer constrained to adopt the narrowly limited viewpoint of an idiot or the distorted vision of a neurotic, we can at last stand back and take in the whole scene" (176); Wolfgang Iser holds that "the identical world of the Compson brothers [is released] from the firstperson point of view" (151); Olga Vickery argues that the novel "emerge[s] from the closed world of the Compson Mile into the public world as represented by Jefferson" (46); and Cleanth Brooks, in a more florid vein, claims that we "break into the sunlight of the world-an objective world. . . Here the solipsism of the private world is expanded into something communal" (25). Yet these assumptions about liberation and enlightenment, about the novel's progress from obscurity to clarity, from privacy to publicity, or from subjectivity to objectivity are assumptions less about the novel than about the nature of signification in general.

Signification itself is at stake in the development of The Sound and the Fury, as Michael Millgate has recognized. He notes that the final section "forces us to view some aspects of the earlier sections in a radically different way" and that "meaning proves on closer inspection to dissolve into uncertainty and paradox" (Millgate 167-171). The development of the novel, or, in other words, the interplay among its parts, is crucial, then, because it represents the level of the text on which meaning at once emerges and dissolves. To address this level of the novel is to confront the uncertainty and paradox of one's own claims about its meaning.

The sort of analysis that has dominated the criticism of this novel confines itself to the semantic level of the text. The syntax of the novel is either condemned as fragmentary and hence flawed or salvaged in a proposition concerning the novel's "development." Yet the syntactic level of the text is not easily extricated from the meaningful, semantic level. In predominantly semantic readings, the peculiar disposition or arrangement of the novel returns, like the repressed, as evidence of an evasion.

By articulating a reading according to the novel's most apparent itinerary or architecture, one may appear to have left the stubbornly divided form of the work pure and intact. Yet the manifest allegiance of section-by-section analyses to the objective form of the work becomes a meaningless and empty gesture, which merely uses form as a readymade, pigeon-holed container for self-presentation. Such presentations fail to acknowledge the fact that the significance they attribute to each ostensibly independent section comes belatedly and from without, that the sections in themselves are largely unintelligible, and that what appears to ameliorate this discomfiting absence of meaning is the play of relations among the individual sections. To represent the dynamics of this novel as a genetic development is not only to reduce a structure productive of countless possible meanings to one decisive meaning and form; it is also to deny the divagations, the sine qua non, of reading The Sound and the Fury.

How have the sections of the novel been traditionally marked off from 
and related to one another? Readers mark the four original sections of the novel off from one another chronologically, according to the date that entitles each part, and perspectivally, according to each narrator. The first section of the original text is thus taken to represent the point of view of Benjy and to take place on April 7, 1928; the next section, the point of view of Quentin on June 2, 1910; and the next, that of Jason on April 6,1928 . The last section is understood to take place on April 8, 1928, but the character of its narrator is not explicit. This narrator has generally been characterized as omniscient, neutral, objective, or, at the very least, less subjective, as Margaret Blanchard points out, before arguing that the narrator of the fourth section is a figure for an ideal or, in other words, acutely perceptive reader $(555,557)$. This figure must be compared, at any rate, with the narrator of the appendix, "a sort of bloodless bibliophile ... [who] knew only what the town could have told him," as Faulkner suggested (Cowley 44). What kind of reader is this bibliophile, who is able to cover, as well as cover up, more than two centuries' time?'

Let us first examine the identification of the sections with the perspectives or points of view of their narrators, by means of which readers evade numerous crises of uncertainty. Many readers presume that although on the one hand the multiplication of points of view makes it impossible to see the novel as a whole from any single point of view, the singular perspective of each section, on the other hand, offers the view of a single unified whole. Because each section represents a different point of view, it is hastily reasoned that each of these sections must constitute a unity of perspective. That the first three sections are cast as soliloquies encourages readers to identify these sections with the subject, particularly with consciousness and with all that has been traditionally thought under its name, that is to say, identity, presence, unity, autonomy, and so on. Because the identification of the first three sections with the characters that narrate them is endemic to the criticism of this novel, I cannot exhaustively describe but rather can illustrate the extent of its consequences.

In a study noted for its attention to the formal structures of this novel, Irena Kaluza states that her aim is to "describe the linguistic structures of The Sound and the Fury in formal categories, that is, ... objectively, and then to find out whether they form a meaningful artistic system in the novel" (8). Kaluza, however, restricts her study of linguistic structures to those that represent "stream-of-consciousness" or, in other words, "mental processes" (8), because, as she notes, her reading has been "moulded" by Vickery, "who treats the four-part structure of the novel as representative of four ways of perceiving experience, dramatizing the

'Faulkner often dated the "present" in his novels to coincide with the time of writing: thus, "1928" in the section titles coincides with the year in which he wrote The Sound and the Fury, and "1945," as the outside date in the title of the appendix, is the year in which he wrote the appendix. 
progression from a private to a public world"' (41). Having decided that the linguistic structures under study correspond to private "ways of perceiving experience," Kaluza must first of all entirely exclude the fourth section and the appendix from consideration. But then, too, she must exclude from the first three sections whatever material cannot be construed as a way of "perceiving experience." Thus, based on the argument that they are "traditional narrative devices" or "directly quoted utterances" (44), as opposed to representations of Benjy's stream of consciousness, Kaluza omits from her study, according to her own calculation, seventy-seven percent of the sentences in the first section. Following the same logic, she excludes from her study of the second and third sections, respectively, "all sentences between two quotation marks ... as well as the accompanying narrative routine units of the "he-said' type" and "all direct utterances contained between two quotation marks" (61, 92).

Kaluza's criterion for separating each narrator's "own" language from "mere" citation or from what she considers a narrative "routine" or "device" underlines the problem raised by the application of such broad and unthought formalistic categories to these sections. As her systematic exclusions point out, the first three sections do not simply or even primarily represent single voices, perceptions of experience, or perspectives.

If such readings reduce the differences of which the first three sections are composed to representations of each narrator as a consciousness, they quickly reach their limits. Whereas systematic omissions make it possible to characterize these sections as "interior monologues," as unities in the form of human subjects, the critic cannot turn to the subject, to character, or to consciousness as a way of accounting for the manners in which the monologues interrelate. Because the monologues are not communicated but uttered in the silence of mental soliloquy, even a model of intersubjectivity is unable to explain what motivates the interaction of the first three sections of the novel. Criticism that refashions the text in the mold of the subject is unable to account for these relations; nevertheless, it employs them in the form of an idealized network of intersubjective relations upon which, in lieu of the literary work, it passes judgment.

Interpretations that identify the first three sections with their narrators are embarrassed by the fourth section of the novel. Unlike the narrators of the "monologues," who are also characters in the novel, the shadowy, anonymous narrator of the fourth section, rather like the narrator of the appendix, hovers in a space and time, that is, in a "world" that the novel does not represent. This embarrassment is turned to advantage when critics argue that the lofty perspective of this otherworldly narrator sees beyond the limited perspectives represented in the monologues and in this manner bridges or relates the monologues to one another. 
As such a medium of totalization and dissolution, the narrative of the fourth section is typically described as broader in scope, explanatory, and clarifying. ${ }^{2}$ In other words, although the fourth section frustrates the totalization of the sections on the grounds of narrative perspective, it is recuperated as the perspective that unites all singular perspectives, dissolving their differences in a higher totality.

Although the novel puts in play the conservative intentions of point of view (self-presence, continuity, unity, autonomy, exclusion of difference, purity, and so on), as well as those of genealogy (lineage, breeding, continuity, transmission of value, purity, exclusion of difference, and such), it challenges rather than confirms their status. Rather than affirming that such constructs can unite what is disparate, the fourth section separates itself off from the other sections of the novel and lends them character through its difference. The appendix, as a genealogical narrative written from a "bibliophilic" point of view, draws out the character of the other sections of the novel by pointing out their difference from and incommensurability with simple genealogy. ${ }^{3}$

Chronology, as I have mentioned, is also invoked to identify and order the sections. The sections are identified with the dates that serve as their titles and are thus understood to take place not in the order they are given but in the sequence their titles can be said to signify: accordingly, the second section ("June SECOND 1910") would come "first," the third section ("APRIL SixTH 1928") would come "second," the first section ("April Seventh, 1928") would come "third," and the fourth section ("APRIL EIGHTH 1928") would remain "fourth" and last. What disturbs the simple reshuffling of the sections is that their given order signifies, if only to signify their difference from chronological order.

The four original sections seem to offer little resistance to such reordering, but the appendix, which is titled "Appendix. Compson 1699-1945," poses a peculiar problem. The dates that appear in the title of the appendix, "1699-1945," which Faulkner wanted typeset like the birth and death dates on a tombstone, include and exceed the time identified with the original sections of the novel. By giving this fifth section a three-part titleat once appendix, patronym, and time span-and by wishing to place the appendix not at the end of the novel but at its beginning, Faulkner draws out many of the contradictions involved in the relationship between a title and the text it entitles. With the appendix, it is difficult to assert that the title establishes the topic and time of the section it entitles. Although the title of the appendix is related to the titles of the other four

\footnotetext{
${ }^{2}$ Even Walter Slatoff, who argues that the fourth section "seems designed not to interpret or to integrate but to leave the various elements of the story in much the same suspension in which they were offered," evaluates the final section in terms of its explicatory relation to the previous sections of the novel (158).

${ }^{3}$ For a "genealogy" of the appendix and its critique of genealogy, see Lester.
} 
sections, it does not function according to the same logic. If the punctual dates of the original sections can be scrambled and restored to chronological order, where is one to locate a time span that engulfs that order? On the basis of the dates in its title, the question of whether to place the appendix first or last is a false question, because neither possibility can reconcile a span of time with a series of points in time. Because it has no place in the order the first four sections can be understood to signify, the appendix is rarely treated as a section in itself but is discussed here and there, with reservations about its status, to bolster particular interpretations of character or chronological order. But the appendix simply draws out what the original sections of the novel already suggest: that is, that this novel opposes itself to the conventional manners in which temporal difference is signified. To examine the novel from the perspective of a temporal order is to relinquish the radical form in which it questions the temporality no less than the spatiality of signification.

A sequential rearrangement of the sections is unable to recognize the specific differences between the sections, even in terms of temporality alone. A simple enumeration of the sections in their "proper" chronological order obscures the basic question of why Faulkner eschewed such an order, as well as a variety of questions raised by the sections' chronological determinations. Why, for example, is the "time" between the sections that are chronologically first and second (June 2, 1910 and April 6, 1928) so much greater than that which separates the others (April 6, 7, and 8)? A chronological reading of the sections has difficulty maintaining the specific differences between such temporal leaps, and it blurs the fact that the temporal differences between the chronologically consecutive sections cannot be expressed as a uniform and formalistic interval. In the order Faulkner gives them, the first section (April 7) is one day after the third (April 6), and the third section (April 6) is two days before the fourth (April 8). But relations of anteriority and posteriority in fact fail to do justice to these interrelations, for each section, taken on its own terms, stakes an equal claim on the present and rearranges the others accordingly. From the perspective of the first section, the third section is the day before; but from the perspective of the third section, the first section is the day after. The fact that the sections' titles may refer to more than one chronological time and to more than one kind of time-to a span of time, to a time before or after, to a first or last time, to a consecrated or a forgotten time-may explain why the sections are most commonly referred to in terms of proper names: as the Benjy section, the Quentin section, the Jason section, and (alas) the fourth section.

Only when the various perspectives raised by the section titles are eliminated in favor of their referral, above all, to the sections "themselves" and when all the sections are therefore understood to partake in the single, 
common element of chronological time do the section titles offer the promise of a medium in which all the individual sections might be united. Time answers to the hope for a form, not quite discovered in consciousness or point of view, that would bring all the sections together in a single, homogeneous medium. Yet such a hope can be fulfilled only by subordinating the novel's complex textualization of time to some unthought notion of Time. In The Sound and the Fury, the essence of time, if that is to be the name for the medium of provisional totality, is nothing simply temporal.

Let us examine the section titles one last time, with reference to the order in which they are given. The only section titles that can be stretched in place to represent a forward-moving, linear sequence or continuum are the first (April 7) and fourth (April 8). Yet, this sequence is interrupted by what stands in the space of its unthinkable middle, a middle or medium without which it could not be a sequence. What comes to light in this space is curiously incompatible with its apparently formal logic, precisely because in this middle semantics and syntax collide. What appears in the middle of this sequence is not the syntactic middle of what its semantic order suggests; indeed, what could or should there be between the 7 th and the 8 th? Conversely, since April 6th appears between the 7 th and the 8th, what appears in the middle of these two dates no longer functions as a satisfactory semantic middle either, as it would if it appeared, say, between the 5th and the 7th. In sum, the construction of a semantic unity invariably opens a middle that exceeds that unity. Semantic unities are thus inhabited and divided by a space that they can neither regulate nor do without. This is the sort of "medium" in whose unruly space and time The Sound and the Fury lets loose its significations.

Because they do not simply add up, line up, or cancel each other out but articulate their differences, the section titles cannot serve to rearrange the novel in the temporal order they at once suggest and disrupt. Like Luster and Benjy, who at the end of the novel double back in disruption around the statute of a Confederate soldier, a monument to a lost cause, the section titles circle around time, which Jason père refers to as "the mausoleum of all hope and desire" (93). Like "point of view," which hovers like a succubus over the voices through which this novel speaks, chronology is in no position to account for the fury of referrals or relays in which it participates and which gives the novel over to the apocryphal stories they lead us to construct. Measurements such as point of view and chronology, failing to account for the relays of which they too are made, can only situate the novel with respect to the very banalities from which it escapes. 
One instance of the sort of illegibility for which The Sound and the Fury is famous occurs toward the end of the first section, when Benjy turns his gaze upon himself. What Benjy gazes upon when he looks at himself is unclear: "I got undressed," we read, "and I looked at myself, and I began to cry." The coincidence of this troubled reaction with Benjy's sight of himself is immediately remarked by Luster: "Hush, Luster said. Looking for them aint going to do no good. They're gone" (90). The significance of Luster's remark is obscure. What, the curious reader must ask, or who, is it useless to look for? Who or what is gone? For the moment, at any rate, it does the reader as little good to ask who or what "they" are as it does Benjy to look for "them."

We can better understand if not explain the puzzles of this passage by pointing out that the antecedent of the objective and subjective pronouns "them" and "they" has been withheld. Certainly, withheld antecedents are familiar to readers of Faulkner, especially to those of us who continue to mull over the dazzling epigraph that introduces Faulkner's second novel, Mosquitoes, in which the author seems to be writing about mosquitoes yet never calls them by their name. Aside from arousing our curiosity and perhaps our irritation, a pronoun that precedes its antecedent has something to say about the topography and chronology of signification.

In the absence of an antecedent, a pronoun is not altogether insignificant. On the contrary, it signifies that it does not in itself indicate what it signifies (in opposition to the manner in which a substantive is held to signify) and, from anyone who cares to know what is intended, it solicits a question. Instead of referring to something, the pronoun invites the reader to ask: "To whom or to what are you referring?" The lack of an antecedent, like a surplus of antecedents, troubles the referring function of the pronoun, but it does not abolish it. Even in the absence of a decidable referent, the pronoun refers. "You are referring," we say to the troublesome pronoun, "but to whom or to what are you referring?" As any handbook makes clear, and as any writing instructor knows only too well, it is the proper placement of the antecedent that allows the pronoun to signify as it should. But in defiance of the grammatical imperative, the pronouns in Luster's reply signify as they do. Because they refer to no neighboring word, because their antecedent or referent is not in the area that precedes them, the reader can only hope to recover their referent in time.

The question we are left with is whether this pronoun will ever recover its "antecedent," but the question we have already forgotten is what Benjy was looking at when he looked at "himself." If I outline a course or itinerary of referrals leading back to this passage and to the antecedents 
of this passage, I must confess from the outset that the latter question will never be answered. It is not simply Benjy's gaze at himself that will lead us back to this passage but the fact that it coincides with Benjy's ambiguous cries and Luster's ambiguous words. It will never be certain that what Benjy was looking at when he looked at himself corresponds to what Benjy began to cry about or to what Luster declared he was looking for. Indeed, what will lead us back to this passage with its long-since forgotten ambiguity will be the very question we have declared ourselves unable to answer: what would Benjy think about when "he'd happen to take a look at himself'?

Because this "backwards" referral comes in the third section, whose title "ApriL Sixth" might be said to indicate the day before the first section, we might have to concede that Faulkner's grammar is correct, after all. The narrator is Jason.

Well at least I could come home one time without finding Ben and that nigger hanging on the gate like a bear and a monkey in the same cage. Just let it come toward sundown and he'd head for the gate like a cow for the barn, hanging onto it and bobbing his head and sort of moaning to himself. That's a hog for punishment for you. If what had happened to him for fooling with open gates had happened to me, I never would want to see another one. I often wondered what he'd be thinking about, down there at the gate, watching the girls going home from school, trying to want something he couldn't even remember he didn't and couldn't want any longer. And what he'd think when they'd be undressing him and he'd happen to take a look at himself and begin to cry like he'd do. But like I say they never did enough of that. I says I know what you need, you need what they did to Ben then you'd behave. And if you don't know what that was I says, ask Dilsey to tell you. (315)

Although this passage may begin to "clarify" the passage we discussed above, it also generates ambiguities in its own right. Which uncertainty is the reader of this passage to focus upon-whit strange composite beast (caged bear/cow/hog) serves to describe Benjy, what happened to Benjy for fooling with open gates, what they never did enough of, why Jason, of all characters, would wonder what Benjy would think, "down there at the gate" or when "they'd be undressing him and he'd happen to take a look" at his naked body, or who Jason addresses when he suggests that "you need what they did to Ben"? Few readers pursue the first and last questions because, unlike the others, they do not promise to efface themselves by clarifying other passages memorable for their obscurity. Few readers choose to puzzle over the odd plurality of animals to which Benjy is compared-not only in this passage from the third section but also in passages from the first section, where Benjy is compared to a hound because he can smell death (41), and from the fourth, where Benjy is compared to a "trained bear" (342)-because such a menagerie interferes with the reader's desire to give Benjy's "voice" a "visible form." Nor do readers question the fact that it is Jason who expresses concern or at least curiosity about what had happened to Ben. It is by way of Jason 
that we are referred back to two previously unconnected passages: one in which Benjy looks at himself undressed and the other in which Benjy "fooled" with the open gate. Jason's remarks newly characterize the passage in which Benjy fooled with the open gate, baptizing it as the antecedent of the passage in which Benjy looked at himself and began to cry. If Jason's remarks "clarify" the relation between these two passages, they also suggest that Jason may have been the architect of their relation. Rather than explaining obscurity away, Jason's remarks introduce new, more sinister obscurities. Still, the reader has become more or less aware, by way of this overcharged chain of referrals, of what critics refer to, in sum, as Benjy's castration. He or she finds out even more when, at the conclusion of the third section, Jason resumes his meditation on what happened to Benjy.

I could hear the Great American Gelding snoring away like a planing mill. I read somewhere they'd fix men that way to give them women's voices. But maybe he didn't know what they'd done to him. I dont reckon he even knew what he had been trying to do, or why Mr Burgess knocked him out with the fence picket. And if they'd just sent him on to Jackson while he was under the ether, he'd never have known the difference. But that would have been too simple for a Compson to think of. Not half complex enough. Having to wait to do it at all until he broke out and tried to run a little girl down on the street with her own father looking at him. Well, like I say they never started soon enough with their cutting, and they quit too quick. I know at least two more that needed something like that, and one of them not over a mile away, either. But then I dont reckon even that would do any good. Like I say once a bitch always a bitch. (328-329)

In order to trace this passage back to the passages with which we are concerned, we must overlook the questions it evokes, questions we will never be in a position to answer: whether Benjy knew "what" they had done to him, who "they" are, and which two people, according to Jason, also needed "something like that." With this passage, the first section's passages about the open gate are clarified both with respect to events that "took place" (Benjy "tried to run a little girl down on the street" and her father, Mr. Burgess, "knocked him out with the fence picket") and with respect to the castration that results from those events ("Gelding," "they'd fix men that way to give them women's voices," "what they'd done to him," "while he was under the ether," "Having to wait to do it," "they never started soon enough with their cutting"). Nevertheless, this passage does not simply clarify select passages from the first section of the novel; rather, it allows certain readers the opportunity to decide upon the significance of passages untranslatable in themselves. The extent to which these previously unintelligible passages are affected by Jason's remarks can be illustrated by a summary Edmond Volpe offers of the passage in which Benjy, as this critic puts it, "assaults the Burgess girl and is castrated." 
Mr. Compson asks Jason if he had left the gate open. Jason denies it, saying the family is bad enough without this kind of thing happening. He tells his father that now he will have to send Benjy to Jackson, that is, if Mr. Burgess does not shoot the idiot first.

The next scene, beginning "It was open when I touched it" presents Benjy's recollection of the incident. The school girls know that the gate is always locked, and they stop to watch Benjy. When the idiot touches the gate, it opens. They run, but he catches one of them.

This memory merges into the castration operation: "and she screamed and I was trying to say and trying and the bright shapes began to stop and I tried to get out. I tried to get it off my face." He is fighting the anesthesia mask, but he breathes in and goes off to sleep. (359; emphasis added)

According to Volpe, Benjy's recollection of the "incident" merges into "the castration operation," but it is more accurate to say that Volpe's description of this passage merges with what certain passages from the third section of the novel allow him to imagine. Yet in order to focus on the significance of these passages one must of course refer to some other passage or passages. In order to give significance to a passage whose referents are either plural or absent, one must locate some "antecedents," if you will. One must turn to other passages in which it is identified or "'marked," as Southern farmers say of castrated livestock. Yet the critic who would in this way mark a passage already marked by its unreadability ought to acknowledge his or her hand in the operation of castration. Volpe, for example, fails to acknowledge that he has identified this passage in a particular manner, excluding not only its own peculiar markings but also any other manner in which it may be marked. Jason's remarks, however dramatic their effect, do not exhaust the referrals into which this passage enters.

Oddly enough, Benjy's "fumbling abortive attempt ... on a passing female child," as this passage is characterized in the appendix (422), is situated at a critical juncture of the first section. At this point in the section, Benjy's movements have come full circle; as at the beginning of the section, he is at the fence, looking at the golf course "through the curling flower spaces" $(1,62)$. What motivates this return to the beginning of the novel? Just before this critical, violent, and confusing "scene," Benjy comes upon Caddy's daughter, Quentin, "in the swing" with a man, and he is reminded of the time he saw Caddy in the swing with Charlie. Benjy's way of describing this sight, as "two now, and then one in the swing" (56), suggests a way of describing the operation of referral, in which otherness leaves its mark. Referral, the swing between two different but related elements, is the most recurrent structure in the novel and is frequently thematized, as it is in this passage, as a crisis. In such crises, the characters of The Sound and the Fury do not recognize but rather suffer the difference between the times and places brought together in the swing of similarity. Benjy has at this point in the section brought together two scenes from whose similarity the narrative seems to flee. As 
if to end itself here once and for all, the narrative returns to its beginning. Yet instead of exploiting the closure of such repetition, as the narrative does in both the second and third sections, the first section suffers its own differences from itself. What "happens" at the open gate marks the unforeseeable difference of the "same."

The passage at the open gate, in which Benjy sees the girls who "passed with their booksatchels," refers the reader to the passage in which Benjy meets Caddy at the gate when she returns from school. In its return to the "same" place, the narrative emphasizes the violence of difference or rather of the failure to recognize difference. Let us examine the passage Jason's remarks in the third section identify as the cause of what "they" did to Benjy:

I went down to the gate, where the girls passed with their booksatchels. They looked at me, walking fast, with their heads turned. I tried to say, but they went on, and I went along the fence, trying to say, and they went faster. Then they were running and I came to the corner of the fence and I couldn't go any further, and I held to the fence, looking after them and trying to say. (63; emphasis added)

The relation of this passage to the passage it attempts to repeat, in which Benjy meets Caddy at the gate, will enable us to hear this passage's emphasis on "trying to say." This phrase draws our attention to the obvious yet nonetheless perplexing paradox of Benjy's voice or point of view, which is incompatible with his incapacity or incompetency. Benjy expresses himself only through inarticulate cries, or in their cessation, yet he employs articulate language in soliloquy. Perhaps the manner in which we understand his soliloquy can be related to the manner in which other characters in the novel "understand" his inarticulate cries. Through his cries, Luster understands that Benjy wants to see the golfers, the flowers, or the fire; Dilsey understands that Benjy smells death; Quentin understands that Benjy doesn't want Caddy to leave; Caddy understands that Benjy thinks it is Christmas, that he wants to hold a letter, that he doesn't like the smell of perfume, and so on. Whether what is understood corresponds to what Benjy means or whether Benjy knows what he means cannot be determined with reference to his soliloquy. What is peculiar to the passage cited above is that Benjy remarks emphatically that he is not crying. Instead, Benjy claims, he is "trying to say." Benjy's distinction continues:

It was open when I touched it, and I held to it in the twilight. I wasn't crying, and I tried to stop, watching the girls coming along in the twilight. I wasn't crying. . . I wasn't crying. . . . They came on in the twilight. I wasn't crying, and I held to the gate. They came slow. . . They came on. I opened the gate and they stopped, turning. I was trying to say, and I caught her, trying to say, and she screamed and $I$ was trying to say and trying and the bright shapes began to stop and I tried to get out. I tried to get it off of my face, but the bright shapes were going again. They were going up the hill to where it fell away and I tried to cry. But when I breathed in, I couldn't breathe out again to cry, and I tried to keep from falling off the hill and I fell off the hill into the bright, whirling shapes. (64; emphasis added) 
To try to understand the difference between crying and trying to say, we cannot turn to "crying," whose significance is decided in particular contexts, by particular characters, and in view of particular interests. Because the significance of Benjy's cries is at once plural and unverifiable, we cannot determine what Benjy means when he says that he is "not crying"' but "trying to say." Yet the way Caddy greets Benjy at the gate suggests a way of greeting the ambiguity of this distinction. When Caddy finds Benjy at the gate, she lets loose a battery of questions:

Did you come to meet me. . . . Did you come to meet Caddy. . . . Did you come to meet Caddy. . . . What is it. What are you trying to tell Caddy. . . . What is it. . . What are you trying to tell Caddy. What is it. $(5-6)$

Caddy's questions are remarkable for their tenacity but also because they lack the punctuation proper to interrogation. In fact, none of the questions posed in the first section bear the mark of interrogation. Still, because the distinction between a declarative and interrogative statement in English is also marked by syntax, we can recognize a question even in the absence of a question mark. Such recognition is simple on the level of the sentence but is considerably more difficult on the level of narration. The narrative is obvious when it forecloses questioning, for example, when Luster points his interlocuter to Benjy, a mute witness, for verification of this or that claim (for instance, 82) or when Caddy interjects answers into her unanswerable interrogation of Benjy, which culminates in a last, unanswerable question:

What is it. . . Did you think it would be Christmas when I came home from school. Is that what you thought. (6)

But the narrative's interrogative thrust, which characterizes, for example, the indeterminable distinction between crying and "trying to say" or between Quentin fille and Caddy in the swing with a man, is more difficult to acknowledge.

It has been argued that Benjy's repetition of "trying to say" is an expression of an urgent desire to communicate. Bleikasten writes that "to speak and be heard [is] the very wish Benjy's monologue is at pains to fulfill. For is not the entire first section a 'trying to say'?" Is not, Bleikasten adds, the entire novel a "trying to say" (83)? Bleikasten interprets "trying to say" in terms of both speaking and being heard because, on the one hand, he cannot be sure which of these very different wishes it refers to and, on the other hand, he projects onto the passage, the section, and indeed the entire novel the wish that speaking and being heard would be the same. But nowhere in The Sound and the Fury is it suggested that the relation between speaking and being heard, between utterance or discourse and comprehension or interpretation, tends toward identity, or even toward a modest felicity. With its congregation of intruding voices 
and sounds, Faulkner's novel affirms nothing so much as the folly and misery of this desire for an illusory identity in communication.

But why should the fundamental separation of the self from itselfwhether one chooses to think of this as castration or as trying to saysurface at this juncture as a crisis? Why should the question of self-identity arise here, at a point the first section could have used to fold back over itself, ending itself in the echo of its beginning, as do the second and third sections? It is here, in its first self-encompassing circle back upon itself, returning to "the curling flower spaces" that the first section discovers that its echoes are not answers but questions. Instead of folding back over itself as though in answer to itself, the novel at this point gives itself over to the recombinatory fury of questions multiplied in the echo of referral. By sustaining referral at the expense of simple reference, as does a pronoun in the absence, excess, or deferral of its antecedent(s), by dwelling on the breaking point of designation, language recasts itself as literature.

When merged with their echoes in the third section, the first section's passages at the open gate are translated into the pseudohistorical cause of Benjy's castration. Yet this "clarification" leads only to other questions, for it obscurely suggests that this cause, too, has a cause. ${ }^{4}$ Reluctant to entertain the interrogatives of this narrative, which are directed, for one thing, at our haste to rectify and dispel its obscurity, placid translations of The Sound and the Fury obscure this novel's furious repetition of its own castration and pacify the violence of its particularly literary affirmation.

\section{WORKS CITED}

Blanchard, Margaret. "The Rhetoric of Communion: Voice in The Sound and the Fury." American Literature 41 (1970): 555-565.

Bleikasten, André. The Most Splendid Failure: Faulkner's "The Sound and the Fury." Bloomington: Indiana UP, 1976.

Brooks, Cleanth. 'Primitivism in The Sound and the Fury.' English Institute Essays, 1952. 1954. Ed. Alan S. Downer. New York: AMS, 1965.

Cowley, Malcolm. The Faulkner-Cowley File: Letters and Memories, 1944-1962. New York: Viking, 1966.

\footnotetext{
'For Jason's possible agency in this history, see 63, 315, 328-329, 422.
} 
Faulkner, William. The Sound and the Fury. 1929. New York: Random, 1956.

Iser, Wolfgang. The Implied Reader: Patterns of Communication in Prose Fiction from Bunyan to Beckett. Baltimore: Johns Hopkins UP, 1974.

Kaluza, Irena. The Functioning of Sentence Structure in the Stream-of-Consciousness Technique of William Faulkner's "The Sound and the Fury": A Study in Linguistic Stylistics. Norwood: Norwood, 1979.

Lester, Cheryl. "To Market, To Market: The Portable Faulkner." Criticism 19 (1987): 371-389.

Millgate, Michael. "The Composition of The Sound and the Fury." Critical Essays on William Faulkner: The Compson Family. Ed. Arthur F. Kinney. Boston: Hall, 1982. 155-172.

Slatoff, Walter. Quest for Failure: A Study of William Faulkner. Ithaca: Cornell UP, 1960.

Stewart, George R., and Joseph M. Backus. " 'Each in Its Ordered Place': Structure and Narrative in 'Benjy's Section' of The Sound and the Fury." American Literature 29 (1958): 440-456.

Vickery, Olga. The Novels of William Faulkner: A Critical Interpretation. Baton Rouge: Louisiana State UP, 1959.

Volpe, Edmond L. A Reader's Guide to William Faulkner. New York: Farrar, 1964. 